\title{
Omuz Problemlerinde Mulligan Mobilizasyon Yönteminin Etkinliği
}

\author{
Effectiveness of Mulligan Mobilization Method in Shoulder Problems

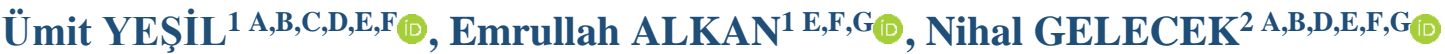 \\ ${ }^{1}$ Dokuz Eylül Üniversitesi, Sağlık Bilimleri Enstitüsü, İzmir, Türkiye \\ ${ }^{2}$ Dokuz Eylül Üniversitesi, Fizik Tedavi ve Rehabilitasyon Yüksekokulu, İzmir, Türkiye
}

ÖZ

\begin{abstract}
Amaç: Ağrı ve hareket kısıtlılığı ile karakterize omuz problemlerinde Mulligan mobilizasyon yönteminin etkinliğinin araştırılmasıdır.

Yöntem: Pubmed, Google Scholar ve Pedro arama motorları konu ile ilgili randomize kontrollü çalışmalar açısından tarandı. Üç araştırmacı başlık, özet ve tam metin makalelerden potansiyel olarak uygun olanları seçmek için dahil edilme kriterlerini birbirlerinden bağımsız olarak uyguladılar.

Bulgular: Kriterlere uyan 26 randomize kontrollü çalışma derlemeye dahil edildi. Literatüre göre Mulligan mobilizasyon yönteminin, rotator manşet sendromlu, subakromiyal sıkışma sendromlu, donuk omuz sendromlu ve omuz ağrılı hastalarda EHA, ağrı ve fonksiyon açısından kısa dönemde etkili olduğu görülmektedir.

Sonuç: Rotator manşet sendromu, subakromiyal sıkışma sendromu, omuz ağrısı ve kısıtlılığı olan hastalar ve donuk omuz sendromu olan hastalarda ağrıyı azaltmak, eklem hareket kısıtlılığını ve fonksiyonu artırmak amacıyla Mulligan mobilizasyon yöntemi kullanılabilir. Mobilizasyonun egzersiz ile birlikte uygulanması daha etkili sonuçlar vermektedir.
\end{abstract}

Anahtar Kelimeler: Mulligan Mobilizasyon, Rotator Manşet, Subakromiyal Sıkışma Sendromu, Donuk Omuz.

\section{ABSTRACT}

Objective: The present study was aimed to investigate effectiveness of Mulligan mobilization method in shoulder problems characterized by pain and restricted range of motion.

Method: PubMed, PEDro and Google Scholar were searched for randomised clinical trials. Three reviewers independently implemented the inclusion criteria to select relevant studies from the title, abstracts and full-text articles.

Results: 26 randomized clinical trials were included in the review. According to the literature, Mulligan mobilization method appears to be effective in the short term in terms of range of motion, pain and function in patients with rotator cuff syndrome, subacromial impingement syndrome, frozen shoulder syndrome and shoulder pain.

Conclusion: Mulligan mobilization method can be used to reduce pain, increase range of motion and function in patients with rotator cuff syndrome, subacromial impingement syndrome, shoulder pain and limitation, and frozen shoulder syndrome. Application of mobilization together with exercise has been shown to be more effective.

Key words: Mulligan Mobilization, Rotator Cuff, Subacromial Impingement Syndrome, Frozen Shoulder.

\section{GİRIŞ}

Omuz eklemi, vücudumuzun en hareketli eklemi olmakla birlikte stabilizasyon desteği en az olan eklemlerimizdendir. Bu nedenle; aşırı kullanma, yetersiz hareket veya aşırı yüklenme, ileri yaş gibi faktörlere bağlı olarak ortaya çıkan omuz eklemi hastalıkları sık karşılaşılan kas-iskelet sistemi problemlerindendir (1). Omuz problemleri içinde de en yaygın olarak Rotator manşet kaslarına ait problemler (Subakromiyal sıkışma sendromu (SASS), supraspinatus tendiniti, rotator manşet tendon yırtıkları vb.), donuk omuz (DO) ve dejeneratif

Sorumlu Yazar: Ümit YEŞİL

Dokuz Eylül Üniversitesi, Sağlik Bilimleri Enstitüsü, İzmir, TÜRKIYYE

fztumityesil@gmail.com

Geliș Tarihi: 23.09.2020 - Kabul Tarihi: 09.01.2021

Yazar Katkıları: A) Fikir/Kavram, B) Tasarım, C) Veri Toplama ve/veya İşleme, D) Analiz ve/veya Yorum, E) Literatür

Taraması, F) Makale Yazımı, G) Eleştirel İnceleme 
omuz eklemi hastalıkları görülmektedir (2). Bu hastalıklar, aynı zamanda çok farklı fizik tedavi ve rehabilitasyon uygulamalarının tedavi amaçlı kullanıldığı ve olumlu sonuçların alındığı hastalıklardan olmaları nedeniyle muskuloskeletal fizyoterapi alanında en fazla literatür çalışmasının olduğu konulardandır (3). Son yıllarda özellikle SASS tanısı ve DO alanında yapılan çalışmalarda birincil bulgular olan ağrının azaltılması, eklem hareket açıklığının arttırılması ve fonksiyonların geliştirilmesinde farklı mobilizasyon yöntemlerinin daha çok öne çıktığı görülmektedir (4).

Rotator Manşet kaslarına ait problemler humerus ile korakoakromiyal ark arasında subakromiyal bursa ve biseps tendonunun uzun başının sıkışması ile oluşur (5). Yaşlılarda genellikle dejeneratif değişikliklerle birlikte görülürken, gençlerde aşırı kullanma veya travmaya bağlı olarak ikincil nedenlerle oluşmaktadır. Rotator manşet yaralanmaları, hastalarda ağrı, omuz hareket açıklığı ve esnekliğinde azalma ve hastanın normal omuz fonksiyonlarında bozulma ile kendini gösterir (6).

Ağrı ve eklem hareket açıklığında kısıtlılık ile seyreden DO, glenohumeral eklemin sık karşılaşılan fakat etyopatogenezi tam olarak aydınlatılamamış rahatsızlığıdır (7). Son yıllardaki çalışmalarda serum sitokin seviyesindeki artışın DO sürecini başlattığ seviyesindeki bu artış hem primer hem de sekonder DO'da inflamasyonun ve fibrozisin nedeni olarak gösterilmiştir. Bu fibröz doku formasyonu ve inflamasyon kapsül, ligamanlar ve rotator intervalde görülmektedir. Artroskopik çalışmalar rotator manşet intervalinin çevresindeki yumuşak dokuların kısaldığını ve sertleştiğini ortaya koymuştur. Rotator manşet intervali anterior supraspinatus tendonu, supskapularisin üst kenarı ve superior glenohumeral ligament ve korakohumeral ligamentten oluşan üçgen bir yapıdır (8).

Mobilizasyon, omuz kapsülünün uzayabilirliğini arttırmak ve kısalmış yumuşak dokuları germek için eklem hareket aralığında herhangi bir yere uygulanan düşük hız ve küçük veya büyük genlikli hareket olarak tanımlanır (4). Literatürde üç tip eklem mobilizasyon tekniği tanımlanmaktadır: ossiliasyonlar, devamlı kuvvet uygulanarak yapılanlar ve manipülasyonlar. Ossiliatuar teknikler, değişken genlikte ve düşük hızda tekrarlayan pasif hareketlerdir. Devamlı kuvvet uygulanarak yapılan mobilizasyonlar, intraartiküler kompresif güçleri azaltan ve periartiküler dokuların gerginliğini ortadan kaldıran değişken genlik ve düşük hızda traksiyon türü hareketlerdir. Bunlar, hareketin genliğine ve periartiküler dokunun gerginlik derecesine göre derecelendirilmiştir. Son olarak, manipülasyon teknikleri, mevcut eklem hareket aralığının sonunda yüksek hızlı, düşük genlikli 'itme' tarzı hareketleri içeren tekniklerdir (9). Manuel terapi yöntemleri eklem hareket açıklığının artırılması ve ağrı azaltılması için önerilmektedir. $\mathrm{Bu}$ tekniklerin, özellikle bir fizyoterapist tarafından sağlandığında kapsüler kısıtlamaların yönetiminde etkili olduğu gösterilmiştir (9).

Mulligan konsepti, ekleme ağırlık taşıyan pozisyonda uygulanan, sürekli kayma (gliding) ve aktif hareket içeren eklem mobilizasyon tekniğidir. Mulligan mobilizasyon tekniği doğal apofizyal kayma (NAGS), devamlı doğal apofizyal kayma (SNAGS) ve hareket ile mobilizasyon (HİM) gibi çeşitli teknikleri içerir (5). HİM'de temel olarak, terapist eklem kısıtlılığını restore edecek doğru açıda devamlı aksesuar kaydırma uygularken, ağrısız ve tam hareket aralığında kısıtlı hareketin aktif olarak yapılmasıdır. Eklem mobilizasyonunun aktif hareket ile kombinasyonu, ağrısız hareketin hızlı geri dönüşünden sorumlu olabilir. HİM'in etkinliğinin arkasındaki mekanizmaların mekanik disfonksiyona ve dolayısıyla pozisyonel hata düzeltmesine dayandığı belirtilmiştir. Bu konsept, yaralanma veya eklem yüzeylerinin 
şeklindeki değişiklikler, kıkırdak kalınlığı gibi sebeplerle ağrı ve sertlik gibi semptomlara yol açan pozisyonel hatalarla ilgilidir. HİM eklemi yeniden normal pozisyonuna getirerek bunu düzeltir (10). Ayrıca HiM'in hipoaljezik etki oluşturduğu ve olası sempato-eksitasyon sağladığı gösterilmiştir (11).

Hing ve arkadaşları, sonuç ölçütleri ağrı, sakatlık ve EHA olan, HİM'in periferik eklemlerde etkinliği ile ilgili sistematik bir inceleme gerçekleştirmiştir. HİM terapatik sonuçlarının çeşitli periferik eklemlerin kas-iskelet sistemi patolojileri ve disfonksiyonları için kabul edilmiş ve yaygın olarak savunulduğu sonucuna varmışlardır (12).

\section{Amaç}

$\mathrm{Bu}$ derlemenin amacı ağrı, hareket kısıtlılı̆̆ı ve fonksiyon kaybı ile karakterize omuz eklemi kas-iskelet sistemi problemlerinde fizyoterapi uygulamaları içinde yaygın kullanılan mobilizasyon yöntemlerinden Mulligan mobilizasyon yönteminin etkinliğinin araştırılmasıdır.

\section{GEREÇ VE YÖNTEM}

Pubmed, Google Scholar ve Pedro arama motorları Ağustos 2020 tarihi itibariyle tarand1. Omuz, subakromiyal sıkışma sendromu (SASS), rotator manşet sendromu, donuk omuz, Mulligan ve HİM (hareket ile mobilizasyon) anahtar kelimeleri kullanıldı. Dahil edilme kriterleri: 1) Omuz ağrısı, SASS, Rotator manşet sendromu veya DO hastalıklarını içermek, 2) Tedavi yöntemi olarak Mulligan mobilizasyon yöntemi kullanılmış olmak, 3) Ağrı, fonksiyon veya EHA değerlendirmeleri içermek, 4) İngilizce ve tam metin olan randomize kontrollü çalışma olmak

Başlangıç aramalarında Pubmed'de 56, Google Scholar'da 183, Pedro'da 19 çalışma bulundu. Kriterlerimize uyan 26 randomize kontrollü çalışma derlemeye dahil edildi. Dahil edilen tam metin makaleler, ayrı incelemelerin yapılabilmesi için farklı hastalık gruplarına ayrıld1. Bu derlemede Mulligan mobilizasyon yönteminin plasebo, geleneksel fizyoterapi veya başka bir mobilizasyon yöntemi ile karşılaştırıldığ çalışmalar incelendi. Üç araştırmacı başlık, özet ve tam metin makalelerden potansiyel olarak uygun olanları seçmek için dahil edilme kriterlerini birbirlerinden bağımsız olarak uyguladılar. Çalışma popülasyonu, yapılan müdahale ve sonuç ölçütlerinden bilgiler topland.

\section{BULGULAR}

\section{Rotator Manşet Sendromu}

Supraspinatus tendiniti olan hastalarla $(n=50)$ yapılan çalışmada, düşük düzey lazer ve ultrason ile birlikte uygulanan HİM tekniğinin ( 8 hafta) ağrıyı azalttığı, omuz fleksiyon ve abduksiyon açılarını arttırdığı gösterilmiştir (13). Başka bir çalışmada rotator manşet sendromlu hastalarda (n=31), HİM ve akupunktur uygulamalarının geleneksel fizyoterapiye (ultrason, TENS, interferansiyel akım, manuel masaj, kriyoterapi veya sıcak paket, kinezyo bant, pendulum egz, aktif ve aktif yardımlı egzersizler, Wand egzersizleri) (10 gün) göre üstünlüğünün olmadığı söylenmiştir (14). Rotator manşet ve SASS'l1 (n=20) hastalarda kinezyo bant ve HİM uygulamalarının egzersiz programına (pendulum egzersizleri, aktif EHA egzersizleri ve izometrik karakterde güçlendirme egzersizleri) (10 gün) göre daha hızlı etki ettiği görülmüştür (15). Geleneksel fizyoterapiye (germe egzersizleri, soğuk paket, ultrason, 
Adnan Menderes Üniversitesi Sağllk Bilimleri Fakültesi Dergisi 2021: 5(2); 380-388

Journal of Adnan Menderes University Health Sciences Faculty

TENS, parmak merdiveni, pendulum egz ve Wand egzersizleri) ek uygulanan HïM'in (n=30, 6 hafta) ağrı, EHA ve yaşam kalitesini olumlu etkilediği saptanmıştır (5).

\section{Subakromiyal Sıkışma Sendromu (SASS)}

SASS '1 1 (n=33) hastalara uygulanan supervize egzersize ilave HIM' in (6 hafta) EHA'y1 artırmada supervize egzersiz (posterior kapsül germe, postural düzeltme egz., rotator manşet güçlendirme ve skapular stabilizasyon egz.), omuz mobilizasyonu ve kontrol grubuna (postural farkındalık ve baş üstü hareketler hakkında eğitim, ev programı) göre daha etkili olduğu, ayrıca manuel terapinin ağrı ve fonksiyon açısından supervize egzersiz ve kontrol grubundan daha etkili olduğu söylenmiştir (16). Başka bir çalışmada bir gruba (n=14) ilk 4 seans HİM, diğer gruba ( $\mathrm{n}=13$ ) sahte HìM uygulanmış, son 4 seans ise ikinci gruba HİM, ilk gruba sahte HİM uygulanmıştır. EHA, ağrı ve fonksiyon açısından iki grup arasında fark bulunmamıştır (17). Bir gruba HİM ( $n=21$ ), diğer gruba sahte HİM ( $n=21$ ) uygulama ( 2 hafta 4 seans) yapılan bir diğer çalışmada ise HİM uygulanan grup ağrı, EHA ve fonksiyon açısından daha iyi bulunmuştur (18). Srivastava ve ark. yaptığı çalışmada HİM grubu $(n=11)$ ve kriyoterapi grubu $(n=11)$ karşılaştırılmıştır (6 seans). İki grup arasında fark bulunmamasına rağmen erken dönemde HİM'in ağrı ve EHA açısından daha etkili olduğu söylenmiştir (19).

\section{Omuz A ğrılı Hastalar}

Neelapala ve ark. yaptığı çalışmada, aktif egzersizlere (fleksiyon, abduksiyon, dış rotasyon, iç rotasyon) ilave uygulanan HİM'in (n=27), erken dönemde ağrı ve diş rotasyon kas kuvveti üzerinde sadece aktif egzersiz uygulananlara göre daha iyi sonuç verdiği görülmüştür, fakat iç rotasyon kas kuvveti ve skapulanın yukarı rotasyonu açısından fark görülmemiştir (20). Başka bir çalışmada omuz ağrısı ve kısıtlılığı olan hastalarda (n=24), HİM'in EHA ve ağrı eşiği üzerinde sahte HİM ve kontrol grubuna göre daha etkili olduğu belirtilmiştir (21). Omuz ağrısı ve kısıtlılığ 1 olan hasta grubunda $(n=25)$ yapılan başka bir çalışma, Mulligan mobilizasyona ilave uygulanan Mulligan bantlama tekniğinin sadece Mulligan uygulamasına (1 hafta) göre daha etkili olduğunu göstermiştir (22). Başka bir çalışmada omuz ağrılı hastalara $(n=44)$ 'hand behind back' tekniğinin egzersizle (terabant ile güçlendirme egz, izometrik egz, posterior kapsül germe) birlikte uygulanmasının (3 hafta 9 seans), ağrı ve fonksiyon üzerinde faydalı olduğu gösterilmiştir (23). Omuz disfonksiyonu olan hastalarda ( $\mathrm{n}=44$ ), fizyoterapiye (postural eğitim, aktif fleksiyon, ekstansiyon ve rotasyon hareketleri) ilave HïM uygulamasının (2 hafta 6 seans), fonksiyon üzerinde yalnızca fizyoterapiye göre daha etkili olduğu belirtilmiştir (24).

\section{Donuk Omuz}

DO'lu hastalarda ( $\mathrm{n}=56$ ) Kaltenborn ve Mulligan mobilizasyonu karşılaştıran çalışma (2 hafta 6 seans) ağrı, EHA ve fonksiyon açısından Kaltenborn mobilizasyonun daha etkili olduğunu göstermiştir (25). Diğer iki çalışma ( $n=40, n=30,10$ seans, 15 seans) ise ağrı, EHA ve fonksiyon bakımından Mulligan mobilizasyon yönteminin Kaltenborn yönteminden daha etkili olduğunu belirtmiştir $(26,27)$. Tip 2 diyabeti olan DO'lu $(n=68)$ hastalarda egzersize ilave HiM'in, sadece egzersizden (pendulum egz., germe ve aktif/aktif yardımlı EHA egz.) (12 hafta 24 seans) daha etkili olduğu saptanmıştır (28). Çalışmalar DO'lu hastalarda ( $n=40, n=30, n=30)$ HİM yönteminin (15 seans) geleneksel fizyoterapiye (sıcak paket, TENS, EHA egz.) göre ağrı, EHA ve fonksiyon bakımından daha etkili olduğunu göstermiştir (29-31). HİM yöntemine ilave 
kas enerji tekniği uygulamalarının ( $\mathrm{n}=30$, 3hafta 18 seans) yalnızca HiM uygulamasından daha etkili olduğu görülmüştür (32). Mulligan ve Maitland yöntemlerinin ( $n=100, n=105)$ (16 seans,20 seans) birbirine üstünlüğünün olmadığını söyleyen çalışmalar varken(33, 34), Mulligan yönteminin ( $\mathrm{n}=30$ ) (24 seans) daha etkili olduğunu söyleyen çalışmalar da mevcuttur (35). Aynı zamanda Mulligan mobilizasyon yönteminin EHA açısından Spencer $(n=40,5$ seans) ve Gong's ( $\mathrm{n}=40,10$ seans) mobilizasyon yöntemlerinden etkili olduğu saptanmıştır (10, 36).

\section{TARTIŞMA}

HIM tekniği, kas-iskelet sistemi hastalıklarında yaygın olarak kullanılmaktadır. Bu derlemede Mulligan yönteminin, omuz problemlerinde ağrı, EHA ve fonksiyona olan etkileri ele alınmıştır. HIM, ağrı azaltılmasında ve EHA artırılmasında umut verici klinik sonuçlar göstermiştir. Bazı çalışmalar bu etkilerin eklemdeki pozisyonel hata düzeltmesinden kaynaklandığını savunurken, bazı çalışmalar HİM'in altında yatan nörofizyolojik mekanizmaları ön plana çıkarmışlardır (37).

Deasi ve ark. yaptığı çalışmada, ultrason ve düşük düzey lazer terapi ile birlikte uygulanan HİM'in ağrıyı azalttığı ve EHA 'yı artırdığı, gruplar karşılaştırıldığında ise ultrason grubunun daha iyi sonuçlar verdiği saptanmıştır. Lazer terapinin daha az etkili olmasını cihazın standart bir kalibrasyonunun olmamasına bağlamışlardır (13). Katana ve ark. geleneksel fizyoterapi ile HIM'e ilave akupunktur uygulanan gruplar arasında WAADL (günlük yaşam aktiviteleri ve iş yeteneği anketi) skoru açısından fark olmadığını bildirmişlerdir (14). Djordjevic ve ark. supervize egzersiz programı ile HIM'e ilave kinezyo bant uygulanan grupları karşılaştırmışlar, 10 günlük süreçte kinezyo bant ve HIMM uygulanan grubun EHA'sının anlamlı olarak daha iyi olduğunu göstermişlerdir (15). Menek ve ark. yaptıkları çalışmada olguları $(n=30)$ iki gruba ayırarak, bir gruba 6 hafta geleneksel fizyoterapi diğer gruba bunlara ilave HİM yöntemi uygulamışlardır. VAS (görsel ağrı skalası), EHA, DASH (kol, omuz ve el sorunları anketi) ve SF-36 (yaşam kalitesi anketi) değerlendirmelerinde HİM uygulanan grubun daha iyi skorlar elde ettiğini vurgulamışlardır (5). Literatürdeki çalışmalara göre Mulligan mobilizasyon yönteminin, rotator manşet hastalıklarında EHA, ağrı ve fonksiyon açısından kısa dönemde etkili olduğu görülmektedir.

Kachingwe ve ark.(16) yaptıkları çalışmada, SASS'lı hastaları supervize egzersiz programı grubu, supervize egzersiz ve glenohumeral eklem mobilizasyonu grubu, supervize egzersiz ve HİM grubu ve kontrol grubu olmak üzere 4 gruba ayırmışlardır. HİM grubu EHA'yı artırmada diğer 3 gruba göre daha etkili bulunmuştur, aynı zamanda HİM ve glenohumeral eklem mobilizasyonunun ağrıyı daha fazla azalttığı tespit edilmiştir. Mulligan yöntemi ve eklem mobilizasyonunun, kapsüler germe sağladığı ve glenohumeral eklem artrokinematiğini restore ettiği vurgulanmıştır. Guimares ve ark. 1.grup (4seans HİM+4 seans sahte HİM) ve 2.grup (4 seans sahte HİM+4 seans HİM) olarak ayrılan gruplar arasında dış rotasyon, abduksiyon, ağrı ve fonksiyon açısından fark bulamamışlar, aynı zamanda uygulamaların fleksiyon, scaption açısı ve kas kuvvetine etkisi olmadığını göstermişlerdir (17). Delgado ve ark. (18) yaptıkları çalışmada (2 hafta 4 seans) ise HİM grubunun, sahte HìM grubuna göre ağrı, fleksiyon ve dış rotasyon açısından istatistiksel olarak daha etkili olduğu saptanmıştır. Çalışmalara göre, SASS'lı hastalarda Mulligan mobilizasyon yöntemi seans zamanından bağımsız olarak EHA ve ağrı üzerinde etkilidir. Srivastava ve ark.(19) iki gruba ayırdıkları 
hastalara egzersiz programına ilave olarak HİM ve kriyoterapi uygulamışlar, 6 hafta sonunda iki grup arasında fark bulunmazken, erken dönemde HİM grubunun EHA, ağrı ve fonksiyon açısından daha önde olduğunu belirtmişlerdir. Mulligan mobilizasyon yönteminin SASS'l1 hastalarda bulunan pozisyonel hatayı hemen düzelttiği için erken dönemde EHA'yı artırdığı iddia edilmiştir. Aynı zamanda merkezi sinir sisteminin analjezik inen yollarını aktive ederek ağrıyı azalttığı öne sürülmüştür (19).

Neelapala ve ark. yaptıkları çalışmada egzersiz grubu ve egzersize ilave HİM uygulanan grubu karşılaştırmışlardır. İki grup karşılaştırıldığında HİM'in dış rotasyon kas kuvveti ve ağrı açısından daha etkili olduğu görülmüş, iç rotasyon kas kuvvetinde ise fark görülmemiştir. Omuz diş rotatörleri ve omuz eklemi ortak bir sinir kaynağı (C5-C6) paylaştıkları için, izometrik dış rotasyon kas kuvvetindeki artışın motor nöronların spinal seviyede uyarılmasına bağlı olabileceğini iddia etmişlerdir. İç rotasyon kas kuvvetinde değişiklik görülmemesini ise iç rotatörlerin ek olarak distal sinir köklerinden (C6-T1) beslenmesine bağlamışlardır (20). Teys ve ark. yaptıkları çalışmada, HİM grubunun, kontrol ve sahte HİM grubuna göre EHA ve ağrı eşiği bakımından daha etkili olduğu saptanmıştır. Ağrılı omuzda öne yer değiştirmiş humerus başının pozisyonunun ağrı ve limitasyonla ilişkili olduğu, Mulligan mobilizasyonun ise pozisyonel hatayı düzelterek ağrıyı ve limitasyonu azalttığını öne sürmüşlerdir (21). Teys ve ark. yaptığı başka bir çalışmada, 1 haftalık süreçte bantlama ile birlikte yapılan HİM'in, sadece HİM uygulanan gruptan ağrı ve EHA açısından daha etkili olduğu görülmüştür (22). Satpute ve ark. yaptığı çalışmada, egzersiz grubu ve HİM grubu (hand behind back tekniği) karşılaştırılmıştır. HİM uygulaması, iç rotasyon açısı ve ağrı bakımından diğer gruba göre daha etkili bulunmuştur (23). Romero ve ark. omuz disfonksiyonu olan hastalarda HİM'in, sadece egzersiz yapılan gruba göre fonksiyon açısından daha etkili olduğunu göstermişlerdir (24). Literatüre göre omuz ağrılı hastalarda Mulligan mobilizasyon yöntemi EHA'yı artırmada, ağrıyı azaltmada kısa dönemde etkilidir, izometrik kas kuvvetini artırdığını iddia eden bir çalışma olsa da bunu kanıtlamak için daha fazla çalışmaya ihtiyaç vardır.

Fernandes ve ark. DO'lu hastalarda Kaltenborn ve Mulligan mobilizasyonu karşılaştırmışlar, iki yöntem de ağrı, EHA ve fonksiyon açısından iyileşme sağlarken Kaltenborn yönteminin Mulligan yöntemine göre üstün olduğunu söylemişlerdir (25). Diğer iki çalışma ise Mulligan yönteminin Kaltenborn'a göre üstün olduğunu iddia etmiştir. Mulligan yönteminin üstün olmasını aktif hareketin eklemdeki refleks kasılmaları inhibe edebileceğine bağlamışlardır. Aynı zamanda Mulligan yönteminin eklemdeki pozisyonel hataları düzelttiğine vurgu yapılmıştır $(26,27)$. Çalışmalar, DO'lu hastalarda Mulligan mobilizasyon yönteminin geleneksel fizyoterapiye göre daha etkili olduğunu göstermiştir (28-30). Nithya ve ark. HİM ile birlikte kullanılan kas enerji tekniklerinin sadece HİM'e göre daha etkili olduğunu göstermişler, bunu HİM'in pozisyonel hatayı düzeltmesine ve kas enerji tekniklerinin kas uzunluğunu restore etmesine bağlamışlardır (32). Ayrıca literatürde Mulligan yönteminin Maitland, Gong's ve Spencer mobilizasyon yöntemlerinden daha etkili olduğunu söyleyen çalışmalar mevcuttur (10, $35,36)$.

\section{SONUÇ}

Rotator manşet sendromu, SASS, omuz ağrısı ve kısıtlılığı olan hastalar ve DO'su olan hastalarda ağrıyı azaltmak, eklem hareket kısıtlılığını ve fonksiyonu artırmak amaciyla Mulligan mobilizasyon yöntemi kullanılabilir. Mobilizasyonun egzersiz ile birlikte 
uygulanması daha etkili sonuçlar vermektedir. Literatürdeki çalışmalar genellikle kısa dönem (3 hafta-3 ay) sonuçlara odaklanmış, uzun dönem (6-12 ay) sonuçlar için daha fazla ve ayrıntılı çalışmalara ihtiyaç vardır.

\section{Çıkar Çatışması}

Yazarlar arasında çıkar çatışması yoktur.

\section{KAYNAKLAR}

1. Linaker, C. H. and Walker-Bone, K., (2015). Shoulder disorders and occupation. Best Pract Res Clin Rheumatol, 29(3), 405-23.

2. Hawk, C., Minkalis, A. L., Khorsan, R., Daniels, C. J., Homack, D., Gliedt, J. A., et all. (2017). Systematic review of nondrug, nonsurgical treatment of shoulder conditions. Journal of manipulative and physiological therapeutics, 40(5), 293-319.

3. Stathopoulos, N., Dimitriadis, Z., and Koumantakis, G. A., (2019). Effectiveness of mulligan's mobilization with movement techniques on range of motion in peripheral joint pathologies: A systematic review with meta-analysis between 2008 and 2018. $J$ Manip Physiol Ther, 42(6), 439-449.

4. Noten, S., et al., (2016). Efficacy of different types of mobilization techniques in patients with primary adhesive capsulitis of the shoulder: A systematic review. Arch Phys Med Rehabil, 97(5), 815-25.

5. Menek, B., Tarakci, D., and Algun, Z. C., (2019). The effect of mulligan mobilization on pain and life quality of patients with rotator cuff syndrome: A randomized controlled trial. J Back Musculoskelet Rehabil, 32(1), 171-178.

6. Akkaya, S., Büker, N., Kitiş, A., Akkaya, N., \& Yörükoğlu, A. Ç. (2010). Rotator manşet lezyonu olan hastalarda ağrı, fonksiyonel durum ve depresyon arasındaki ilişkinin incelenmesi. Pamukkale Tıp Dergisi, (2), 84-89.

7. Atıc1, T., ve ark., (2013). Donuk Omuz: Tan1-Tedavi. Uludağ Üniversitesi Tıp Fakültesi Dergisi, 39(3), 211-218.

8. Çelik, D., (2017). Donuk omuz ve rehabilitasyonu. Turkiye Klinikleri Physiotherapy and Rehabilitation - Special Topics, 3(1), 9-23.

9. Zavala-González, J., Pavez-Baeza, F., Gutiérrez-Espinoza, H., \& Olguín-Huerta, C. (2018). The effectiveness of joint mobilization techniques for range of motion in adult patients with primary adhesive capsulitis of the shoulder: a systematic review and metaanalysis. Medwave, 18(5), 65-72.

10. Khyathi, P., Babu, V. K., Kumar, S., \& Asha, D. (2015). Comparative effect of spencer technique versus mulligan's technique for subjects with frozen shoulder-a single blind study. International Journal of Physiotherapy., 2(2), 448-458.

11. Paungmali, A., O'Leary, S., Souvlis, T., \& Vicenzino, B. (2003). Hypoalgesic and sympathoexcitatory effects of mobilization with movement for lateral epicondylalgia. Phys Ther, 83(4), 83-374.

12. Hing, W., Bigelow, R., and Bremner, T., (2009). Mulligan's mobilization with movement: A systematic review. J. Man. Manip. Ther., 17(2), 39-66.

13. Desai, P. and Vinodkumar, A., (2016). A comparative study between efficacy of low level laser therapy (LLLT) with mulligan's mobilization (MWM) over ultrasound therapy with mulligan's mobilization (MWM) in patients with acute supraspinatus tendinitis. Indian Journal of Physiotherapy and Occupational Therapy, 10, 75-81. 
14. Katana, B., Pašalić, A., Jaganjac, A., Hadžiomerović, A. M., Bojičić, S., Avdic, D., et al., (2018). The efficiency of the conventional physical treatment of the shoulder pain compared to conventional treatment plus the mulligan's joint mobilization technique and acupuncture. Journal of Health Sciences, 8(2), 88-93

15. Djordjevic, O. C., Vukicevic, D., Katunac, L., \& Jovic, S. (2012). Mobilization with movement and kinesiotaping compared with a supervised exercise program for painful shoulder: Results of a clinical trial. J Manipulative Physiol Ther, 35(6), 63-454.

16. Kachingwe, A. F., Phillips, B., Sletten, E., \& Plunkett, S. W. (2008). Comparison of manual therapy techniques with therapeutic exercise in the treatment of shoulder impingement: A randomized controlled pilot clinical trial. J. Man. Manip. Ther., 16(4), 238-247.

17. Guimarães, J. F., Salvini, T. F., Siqueira Jr, A. L., Ribeiro, I. L., Camargo, P. R., \& Alburquerque-Sendín, F. (2016). Immediate effects of mobilization with movement vs sham technique on range of motion, strength, and function in patients with shoulder impingement syndrome: Randomized clinical trial. J Manipulative Physiol Ther, 39(9), 605-615.

18. Delgado-Gil, J. A., Prado-Robles, E., Rodrigues-de-Souza, D. P., Cleland, J. A., Fernández-de-las-Peñas, C., \& Alburquerque-Sendín, F. (2015). Effects of mobilization with movement on pain and range of motion in patients with unilateral shoulder impingement syndrome: A randomized controlled trial. $J$ Manipulative Physiol Ther, 38(4), 52-245.

19. Srivastava, S., Eapen, C., and Mittal, H., (2018). Comparison of mobilisation with movement and cryotherapy in shoulder impingement syndrome-a randomised clinical trial. J. Clin. Diagnostic Res., 12, 1-5.

20. Neelapala, Y. V. R., Reddy, R. S. Y., and Danait, R., (2017). Effect of mulligan's posterolateral glide on shoulder rotator strength, scapular upward rotation in shoulder pain subjects - a randomized controlled trial. Journal of Musculoskeletal Research., 19(3), 1-11

21. Teys, P., Bisset, L., and Vicenzino, B., (2008). The initial effects of a mulligan's mobilization with movement technique on range of movement and pressure pain threshold in pain-limited shoulders. Man Ther, 13(1), 37-42.

22. Teys, P., Bisset, L., Collins, N., Coombes, B., \& Vicenzino, B. (2013). One-week time course of the effects of mulligan's mobilisation with movement and taping in painful shoulders. Man Ther, 18(5), 7-372.

23. Satpute, K.H., Bhandari, P., and Hall, T., (2015). Efficacy of hand behind back mobilization with movement for acute shoulder pain and movement impairment: A randomized controlled trial. J Manipulative Physiol Ther, 38(5), 34-324.

24. Romero, C. L., Lacomba, M. T., Montoro, Y. C., Merino, D. P., da Costa, S. P., Marchante, M. J. V., et all. (2015). Mobilization with movement for shoulder dysfunction in older adults: A pilot trial. Journal of Chiropractic Medicine, 14(4), 249258.

25. Fernandes, A. and LakshitaShah, A., (2020). Effectiveness of kaltenborn mobilization technique versus mulligan's mwm in patients with adhesive capsulitis of shoulder. Indian Journal of Physiotherapy and Occupational Therapy, 14(3), 18-24.

26. Rathod, D., Priyanka, G., and Palkar, A., (2019). Comparative study of kaltenborn mobilisation versus mulligan mobilisation in patients with frozen shoulder. International Journal of Health Sciences and Research, 9(9), 320-324.

27. Ragav, S. and Singh, A., (2019). Comparison of effectiveness of mulligan 'MWM' technique versus kaltenborn mobilization technique on pain and end range of motion in 
patients with adhesive capsulitis of shoulder joint: A randomized controlled trial. Journal of Exercise Science \& Physiotherapy, 15(1), 1-9

28. Sai, K. V. and Kumar, J. S., (2015). Effects of mulligan's mobilisation with movement on pain and range of motion in diabetic frozen shoulder a randomized clinical trail. Indian Journal of Physiotherapy and Occupational Therapy, 9(4), 187-193.

29. Reddy, B. C. and Metgud, S., (2015). Randomized controlled trial to investigate the effect of mulligan's mwm and conventional therapy in stage ii adhesive capsulitis. Indian Journal Of Physical Therapy, 3, 55-549.

30. Doner, G., Guven, Z., Atalay, A., \& Celiker, R. (2013). Evaluation of mulligan's technique for adhesive capsulitis of the shoulder. J Rehabil Med, 45(1), 87-91.

31. Yeole, U. L., Dighe, P. D., Gharote, G. M., Panse, R. S., Shweta, A. K., \& Pawar, P. A. (2017). Effectiveness of movement with mobilization in adhesive capsulitis of shoulder: Randomized controlled trial. Indian Journal of Medical Research and Pharmaceutical Sciences, 4(2), 1-8.

32. Nithya, J., Saketa, J., and Hannah, R., (2019). Efficacy of muscle energy techniques as an adjunct with mulligans mobilization in adhesive capsulitis of shoulder. International Journal of Physiotherapy, 6(2), 52-57

33. Arshad, H., Hussain Shah, S. I., and Nasir, R., (2015). Comparison of mulligan mobilization with movement and end-range mobilization following maitland techniques in patients with frozen shoulder in improving range of motion. International Journal of Science and Research, 4(4), 2761-2767

34. Jeyakumar, S. and Alagesan, J., (2018). Comparative study of effects of maitland technique and mulligan technique in adhesive capsulitis of shoulder. International Journal of Medical Research \& Health Sciences, 7(5), 1-10.

35. Biswas, S. and Biswas, S., (2018). Comparative study to find out the effectiveness of maitland mobilisation versus mulligan mobilisation with common use of ultrasound therapy in patients with shoulder adhesive capsulitis-pathoanatomical study. Journal of Evolution of Medical and Dental Sciences, 7(4), 529-534.

36. Dilip, J. R., Babu, V. K., Kumar, S. N., \& Akalwadi, A. (2016). Effect of gong's mobilization versus mulligan's mobilization on shoulder pain and shoulder medial rotation mobility in frozen shoulder. International Journal Of Physiotherapy, 3(1), 132139.

37. Westad, K., Tjoestolvsen, F., and Hebron, C., (2019). The effectiveness of Mulligan's mobilisation with movement (MWM) on peripheral joints in musculoskeletal (MSK) conditions: A systematic review. Musculoskelet Sci Pract, 39, 157-163. 